\title{
INTERNET ADDICTION AND MENTAL HEALTH STATUS OF ADOLESCENTS IN CROATIA AND GERMANY
}

\author{
Silvana Karacic $^{1} \&$ Stjepan Oreskovic ${ }^{2}$ \\ ${ }^{1}$ Healthy centar Sveti Kriz Trogir, Trogir, Croatia \\ ${ }^{2}$ University of Zagreb, School of Medicine, Zagreb, Croatia
}

received: 24.10.2016;

revised: 19.4.2017;

accepted: 22.5 .2017

\begin{abstract}
SUMMARY
Background: The research examines the influence of internet addiction of adolescents in Croatia and Germany and its impact on the subjective feeling of health status. The purpose of this paper is also to give insight into how the Internet addiction which is a risky health behavior affects the health status of adolescents. The excessive use of Internet is linked with the lower health status of Croatian adolescents as well as of the adolescents in Germany.

Subjects and methods: Respondents are defined as students who attend school regularly ages 11-18. The modified SF-36 questionnaire and IAT for Internet addiction were used.

Results: The Spearman correlation coefficient was calculated -0.23 with $N=459$ and $p<0.001$. Accordingly, the correlation between health quality and Internet addiction is negative but statistically significant $(p<0.001)$.

Conclusion: There is a strong correlation between adolescents' mental health and quality of life and the level of their Internet addiction. Out of the total number of adolescents in ill-health, 39\% of them are moderately or severely addicted to the Internet. $20 \%$ out of the total number of adolescents in medium health is moderate of severely addicted to the Internet. Finally, out of the total number of adolescents in good health 13\% has been moderate of highly addicted to the Internet. Therefore, the better the adolescents' health, the fewer the Internet addicts. And vice versa, the worse the health, the more the Internet addicts.
\end{abstract}

Key words: mental health status - Internet - addiction - adolescents

$* * * * *$

\section{INTRODUCTION}

The modern way of life, computerization and the influence of Internet lead to the change of way of life from the earliest age. The risk factors of man's health are imposed upon from an early phase of adolescence. Adolescence is a period of adjustment, a time of physical and emotional changes and changes in behaviour. It is a stressful life period where even the normal maturing gait includes a certain amount of emotional disturbance, as to oneself, so unto others. Adolescence is also a phase of developing an identity and building peer relationships so their online activities mainly focus on interacting with peers (Steffes-Hansenb \& Tsaoa 2008). For precisely this reason, the Internet, as a leading form of mass media, greatly affects the risk behavior of young people and consequently their health status. Recently, psychosomatic symptoms are becoming more frequent in adolescent populations (Santalahti et al. 2005). A study conducted in Finland showed an increase of symptoms over a 10 -year period resulting from stressful life occurrences and changes in the way of life of young people. Playing video games has presented itself as a strong risk factor for development of headaches and migraines (Xavier et al. 2015). Excessive Internet use leads to neglect of usual life habits; increasing amounts of time spent online have consequences for one's health. The most common physical symptoms are pain, stiffness in arms and joints, dry and strained eyes, back-pain, neck-pain leading to headache, sleeping disorder, extreme hyperactivity, excessive talkativeness, decreases in hygiene, and eating disorders (Saisan et al. 2012). As a form of eating disorder in adolescents, obesity demands attention all by itself, but also for its direct and indirect influence on morbidity and the expectance of life duration (Saisan et al. 2012, Guo et al. 2002). Greater static burdening originating from long-term sitting at a computer can be dangerous for posture and young people's health. The second most common causes of taking sick-leave are degenerative changes in the spine and spinal pain (Chuang 2006). Internet addiction is a type of psychological addiction and is defined as a form of behavior that is linked to persistence in an activity that causes decreases in health, social functioning, and quality of life. Research on Internet addiction and social deviance has occurred on a global scale in the last 20 years, especially in the frameworks of social psychology, medical sociology, and other public health disciplines. It shows that about $11 \%$ of all people using the Internet become addicted to it or show some compulsive behavior related to it. Findings from this research are very applicable in contemporary methodologies aiming at the betterment of physical or psychological well-being and improvements in social relations. The effectiveness of adolescent health services are evaluated by measures of health status, so we can clearly determine targets for action by assessing the broad spectrum of health including 
mobility, general functioning, mental health, and total well-being. The aim is to identify the health problems and needs of vulnerable adolescent groups, particularly Internet addicts who experience a certain degree of pleasure when using the Internet, and mostly psychological symptoms like discomfort, anxiety, and depression when they stop using it. The health status rating depends on individual assessment based on the complete psychological structure of an individual in interaction with their social environment. However, there are multiple effects on health; hence, a broad research health model is required. Besides biological factors, health or the outcome of disease is also influenced by non-biological factors - the individual's personality, motivation, socioeconomic status, availability of medical protection, network of social support, individual and cultural beliefs, and behavior. These non-biological factors are reflected in newer indicators of so called subjective health (Bowling 1991). In the majority of survey studies or broader clinical trials, one's health condition is operationalized as self-assessment of own health or as functional capability. The answer to a seemingly simple question about one's general health provides information about life expectancy of an individual - information that is difficult to acquire with detailed assessments of medical conditions and problems (Rakowski et al. 1994). General self-assessment of health is a subjective measure that cannot be confirmed objectively. Many researchers consider assessments to be "objective" if they can be medically checked, if needed (Idler 1992). If the respondent provides information about his or her "objective" health, there is a danger that responses may be influenced by personality characteristics, such as self-respect, patient role, perception of control over own health, and so on. Therefore, "objective" health assessments must not be taken as completely objective measures, but still be considered distinct from subjective health self-assessment. If there really is a mutual, overlooked factor underlying both objective and subjective health assessments, one can assume it will act the same way in both assessments. A person's health depends on several factors: heritage, social context in which one lives, one's medical behavior, and the medical system of one's country (Lalonde 1974). Research shows that risky health behavior is mostly acquired during schooling (Harris et al. 2006). In most cases, changes of risky health behavior occur due to awareness of information and environmental pressure (Satia et al. 2001). The purpose of this research is to contribute to understanding of individual health factors, primarily the behavior of excessive Internet use as a risky health habit, as well as the self-assessment of subjective feelings of adolescent's health. Social health determinants are not only important for scientific research, they are also taken into consideration when formulating developmental health strategies in particular countries (Wilkinson \& Marmot 2003). Furthermore, behavior and lifestyle are important health factors, and depend on the conditions in which one lives. Health analysis cannot be conducted without examining health behavior and risky habits. Seeing that social environment and surroundings are important health factors, the research examined the influence of country of in adolescents in Croatia and Germany, and their relationship to subjective feelings of health status. The aim of the paper is also to examine how a risky health habit, Internet addiction, affects adolescent health status. The SF-36 questionnaire proved very practical in measuring the subjective feeling of mental health due to a firm connection with the most common mental disorders (anxiety, depression) (Weinstein et al. 1989, Rumpf et al. 2001). Anxiety and depression are, among other things, disorders that occur as a consequence of Internet addiction.

\section{Hypothesis and Research goals}

H1 - Excessive use of Internet is related to lower health status, in both Croatian and German adolescents.

The primary objective of the research is to examine the health status perception of adolescents in Croatia and Germany.

\section{SUBJECTS AND METHODS}

Participants were drawn from students aged 11-18 who attend school regularly. The study included 667 students of primary and high school from Croatia and Germany.

The following schools took part in the research: Oštrog Kaštel Lukšić elementary school from Croatia; Velika Gorica grammar school, Ulica kralja S. Tomašić, Velika Gorica from Croatia; Humboldt-Gymnasium Vaterstaetten, Johann Strauß Straße 41, 85598 Baldham from Germany.

An invitation to participate in the research was sent to the schools explaining that complete privacy of the students would be maintained and that participation would occur only with the informed consent of the student, a parent, or a guardian. The questionnaire was posted in Google Documents. On the front page, participants were instructed to complete the questionnaire sincerely and fully. They were notified that the questionnaire is anonymous and that the data would be used exclusively for research purposes. They then completed the questionnaire during their computer science classes; questionnaires took about 10 minutes. The research was performed with the consent of the school's ethics committee.

The survey has three parts, each of which has undergone the standardized procedure of double translation of the questionnaire for both countries.

\section{General information}

Demographic measures used in the research include age, gender, and country of residence. 


\section{Internet addiction}

Internet addiction was assessed with Young's IAT (Internet Addiction Test) for which I have approval and a license from Dr. Kymberly Young (1998). The questionnaire contains 20 questions based on criteria for pathological gambling. These 20 questions reflect typical addictive behaviors. Widiyamto and McMurran report that the scale mirrors six dimensions of Internet addiction: preoccupation, salience, excessive Internet use, neglect of obligations/work, anticipation, lack of self-control, and neglect of social life (Widyanto \& McMurran 2004).

Degrees of Internet addiction have been classified using a points scale; the scoring range is 20-100: (a) 2049 points - normal, (b) 50-79 points - moderate addiction, and (c) 80-100 points - severe addiction.

Every question scores up to 5 points, with 1 point for very rare, 2 for rarely, 3 for often, 4 for very often, 5 for always. The scale shows very good internal consistency; Cronbach's alpha coefficient is 0.93 in the current study.

\section{Health status}

Health status was measured by the Short Form (36item) Health Survey (SF-36), a survey for assessment of individual's health status that consists of 10 questions. The SF-36 has proved very practical in measuring subjective feelings of mental health due to a firm connection with the most common mental disorders (anxiety and depression) (Weinstein et al. 1989, Rumpf et al. 2001), that are known consequences of Internet addiction. The SF-36 questionnaire for physical functioning was modified for the purpose of this research. The questions have multiple answers. Specific answers on every matter are scored differently. Therefore, the number of scored points marked at every question of the questionnaire was transformed into standard values and gauged to a unique scale of minimum 0 and maximum 30 points, with higher numbers representing better health. For every question or claim, the respondent circled the answer on the scale according to his or her subjective assessment.

\section{Data processing}

A software package for social research, SPSS, was used for statistical processing. Two groups of methods were used in data analysis: descriptive statistical analysis (relative numbers, medium values, and dispersion measurements), and inferential statistical analysis (Chisquare test, T-test, and analysis of variance).

\section{RESULTS}

There were 667 people from Croatia and Germany included in the study. After eliminating 97 respondents for missing mandatory data, the remaining sample consisted of 570 people, 401 from Croatia, and 169 from Germany. The majority of participants were girls (64\%); a little over a third were boys (36\%). Respondents' ages varied between 11 and 18 . The most prevalent age was 15 years old, in both Croatia and Germany. Therefore the modal and median age values were 15 years. Demographic characteristics of the participants are graphically displayed in Figure 1.

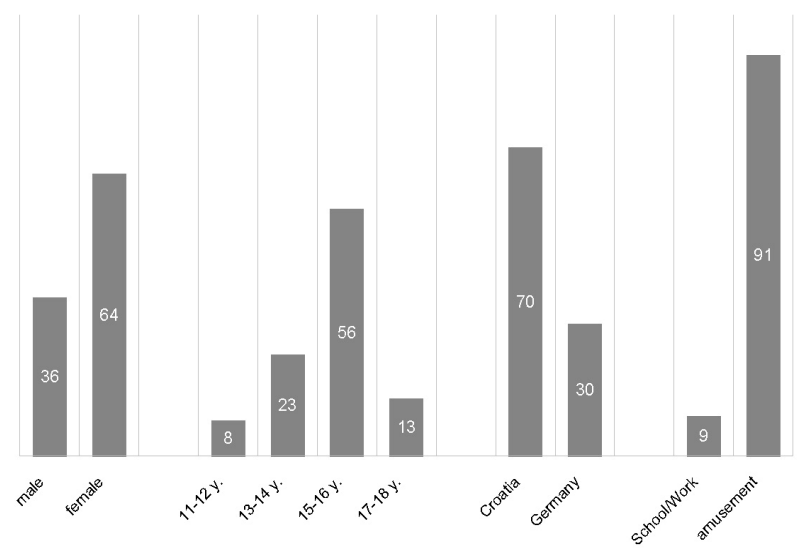

Figure 1. Characteristics of participants including gender, age, origin, and purpose of use (expressed in percentages)

\section{Statistical analysis of participants' health status}

The answers to the questions about adolescents' perception of their health status in the questionnaire are displayed in 4 tables considering offered answers had up to $2,3,4$, or 5 possible responses.

Table 1 provides a general overview of participants' self-assessed health. In this table, data from the categories "much better" and "little better" have been combined under the heading "\% better," while data from the categories "little worse" and "much worse." have been combined under the heading "\% worse." These two terms are also used in further analyses. Percentages for the "about the same" category have not been separately displayed.

Adolescents from Croatia and Germany, most of whom are Internet users, rated their health as average (category "about the same"). Based on relative frequencies, ratings of German adolescents are slightly better, slightly more optimistic, in comparison to Croatian adolescents (first two questions of total health evaluation, i.e., the general perception of health).

Table 2 shows that Croatian and German adolescents have relatively low rates of the health problems listed, with an average $9 \%$ of participants reporting problems. Some types of pain rarely appear $6 \%$ mention neck pain) while some appear more often (a headache mentioned by $15 \%$ of respondents, back pain stated by $13 \%)$. Table 2 also shows differences between pain reported by Croatian (7\%) and German (14\%) adolescents respectively. German adolescents are two times more likely to have pain than their Croatian peers. Close examination of the last column in Table 2 shows that this extends to all types of pain apart from neck pain. 
Table 1. Adolescents' subjective health self-assessment $(\mathrm{N}=570)$ according to general ratings and country of origin

\begin{tabular}{|c|c|c|c|c|c|c|c|c|c|c|}
\hline $\begin{array}{l}\text { Question } \\
\text { number }\end{array}$ & General health self-assessment & $\begin{array}{l}\text { Adolescent } \\
\text { group }\end{array}$ & $\begin{array}{l}\text { Much } \\
\text { better }\end{array}$ & $\begin{array}{l}\text { Little } \\
\text { better }\end{array}$ & $\begin{array}{l}\text { About } \\
\text { the same }\end{array}$ & $\begin{array}{l}\text { Little } \\
\text { worse }\end{array}$ & $\begin{array}{l}\text { Much } \\
\text { worse }\end{array}$ & Total & $\begin{array}{c}\% \\
\text { better }\end{array}$ & $\begin{array}{c}\% \\
\text { worse } \\
\end{array}$ \\
\hline \multirow[t]{2}{*}{1.} & \multirow{2}{*}{$\begin{array}{l}\text { General evaluation } \\
\text { of own health }\end{array}$} & Cro & 109 & 53 & 180 & 11 & 7 & 360 & 45 & 5 \\
\hline & & Germany & 52 & 31 & 55 & 8 & 4 & 150 & 55 & 8 \\
\hline \multirow[t]{2}{*}{2.} & \multirow{2}{*}{$\begin{array}{l}\text { Evaluation of own health com- } \\
\text { pared to the health of peers }\end{array}$} & Croatia & 70 & 85 & 175 & 20 & 7 & 357 & 43 & 8 \\
\hline & & Germany & 40 & 51 & 53 & 7 & 4 & 155 & 59 & 7 \\
\hline \multirow[t]{2}{*}{3.} & \multirow{2}{*}{$\begin{array}{l}\text { Evaluation of own health } \\
\text { compared to last year }\end{array}$} & Croa & 87 & 74 & 161 & 29 & 6 & 357 & 45 & 10 \\
\hline & & Germany & 27 & 31 & 79 & 14 & 5 & 156 & 37 & 12 \\
\hline
\end{tabular}

Table 2. Adolescents' health problems causing difficulty in everyday activities $(\mathrm{N}=570)$ according to types of problems and country of origin

\begin{tabular}{cllrrrrr}
\hline Question number & Health problem & Adolescent group & A lot & Little & Not at all & Total & $\%$ A lot \\
\hline 4. & Neck pain & Croatia & 23 & 112 & 225 & 360 & 6 \\
& & Germany & 10 & 29 & 116 & 155 & 6 \\
5. & Pain and numbness in arms & Croatia & 10 & 46 & 301 & 357 & 3 \\
& & Germany & 19 & 22 & 114 & 155 & 12 \\
6. & Shoulder pain & Croatia & 16 & 81 & 258 & 355 & 5 \\
& & Germany & 18 & 42 & 94 & 154 & 12 \\
7. & Back pain & Croatia & 41 & 138 & 176 & 355 & 12 \\
& & Germany & 27 & 42 & 83 & 152 & 18 \\
8. & & Croatia & 26 & 96 & 236 & 358 & 7 \\
9. & Eye pain & Germany & 18 & 34 & 102 & 154 & 12 \\
& & Croatia & 17 & 103 & 236 & 356 & 5 \\
10. & Headaches & Germany & 17 & 27 & 109 & 153 & 11 \\
& & Croatia & 38 & 139 & 181 & 358 & 11 \\
\hline
\end{tabular}

Table 3. Number of adolescents who had physical or emotional problems that obstructed everyday activities in the last 4 weeks $(\mathrm{N}=570)$ - according to types of consequences and country of origin

\begin{tabular}{cllrrrr}
\hline Question number & Consequence of physical health problem & Adolescent group & No & Yes & Total & \% Yes \\
\hline \multirow{2}{*}{11.} & Reduced time spent working & Croatia & 278 & 74 & 352 & 79 \\
& and at other activities & Germany & 125 & 30 & 155 & 81 \\
12. & Amount performed less than desired & Croatia & 237 & 114 & 351 & 68 \\
& & Germany & 109 & 43 & 152 & 72 \\
13. & Inability to perform work and other & Croatia & 280 & 73 & 353 & 79 \\
& activities & Germany & 61 & 94 & 155 & 39 \\
14. & Difficulties with work or other activities & Croatia & 272 & 79 & 351 & 77 \\
& & Germany & 123 & 30 & 153 & 80 \\
15. & Reduced time spent at other activities & Croatia & 277 & 79 & 356 & 78 \\
& & Germany & 118 & 34 & 152 & 78 \\
16. & Amount performed less than desired & Croatia & 268 & 87 & 355 \\
& & Germany & 119 & 33 & 152 & 75 \\
17. & Inability to perform work and other & Croatia & 256 & 95 & 351 & 73 \\
\hline
\end{tabular}

Table 3 lists respondents' answers as to whether they felt physical health problems (questions 11-14) or emotional problems (questions 15-17) that obstructed their everyday activities in the last month.

Table 3 shows that a relatively large percentage $(76 \%)$ of adolescents have experienced consequences due to their health and emotional issues. This applied to $76 \%$ of Croatian and $67 \%$ of German adolescents respectively. Inability to perform some work and other activities due to physical health (question 13) and emotional difficulties (question 17) respectively, were more common in Croatian adolescents than in German ones. For almost every other health problem consequence, the reverse relationship is apparent, that is consequences appear more often in German than in Croatian adolescents. 
Table 4. Survey answers of adolescents who had some of physical and emotional health problems in the last 4 weeks $(\mathrm{N}=570)$ according to strength of influence and country of origin

\begin{tabular}{cllrrrrrrr}
\hline $\begin{array}{l}\text { Question } \\
\text { number }\end{array}$ & Type of influence & $\begin{array}{l}\text { Adolescent } \\
\text { group }\end{array}$ & $\begin{array}{l}\text { Not } \\
\text { at all }\end{array}$ & $\begin{array}{c}\text { To a lesser } \\
\text { extent }\end{array}$ & $\begin{array}{l}\text { Mode- Quite signi- } \\
\text { rately }\end{array}$ & $\begin{array}{c}\text { Total } \\
\text { ficantly }\end{array}$ & $\begin{array}{c}\text { \% Not } \\
\text { at all }\end{array}$ & $\begin{array}{c}\text { \% Quite } \\
\text { significantly }\end{array}$ \\
\hline 18. & On usual social activities with & Croatia & 219 & 75 & 40 & 16 & 350 & 63 & 5 \\
& family, friends, neighbors etc. & Germany & 95 & 29 & 22 & 9 & 155 & 61 & 6 \\
19. & On thwarting habitual work & Croatia & 212 & 88 & 38 & 13 & 351 & 60 & 4 \\
& in and outside of home & Germany & 92 & 36 & 15 & 9 & 152 & 61 & 6 \\
\hline
\end{tabular}

Table 4 shows that for a majority of adolescents (61\%) physical and emotional health did not create any problems in everyday life whatsoever. On the other hand, $5 \%$ of adolescents experience problems quite often. Furthermore, it is noticeable that there are no large differences between Croatian and German adolescents in these percentages, as the values are very close.

The recent intensity of adolescents' feelings, positive as well as negative, was assessed in a series of 9 questions. Answers had five possible responses, ranging from significantly to never.

Croatian and German adolescents experienced positive feelings at a similar frequency. About half of all adolescents from both countries have had these kinds of feelings either often or almost always.

Croatian and German adolescents experienced negative feelings at a similar frequency. Specifically, $2 / 3$ of adolescents from both countries rarely or never have negative feelings.

\section{Statistical analysis of health status data}

A composite score of participants' health quality was constructed based on their answer scores for all 30 questions. Each question was scored from 0-100, where 0 indicates the poorest level of health and 100 indicates the maximum level of health. Respondents with the best health and answers to all 30 questions would have a maximum total score of 3000 points (30 questions $\mathrm{x} 100$ points per question $=3000$ points), while those with the worst health and answers to all 30 questions would have a total score of 0 points.

Adolescent health composite scores ranged between 210 and 2550 points, with a mean of 1771 for 521 participants. The median was 1805 , while the standard deviation was 330.5, representing a smaller dispersion (variation coefficient is 19\%). That means that the observed group of adolescents was relatively homogeneous, given their health. The normality of the distribution of the composite scores was checked using the Kolmogorov-Smirnov test. According to the results of that test $(\mathrm{z}=0.099 ; \mathrm{df}=521 ; \mathrm{P}<0.001)$, the distribution was not normal, which is a common occurrence in studies with a larger number of test subjects. The distribution showed negative skew, as shown in the histogram (Figure 2). The composite health scores can be used to compare the health of adolescents of different genders, origins, and ages. Independent samples t-tests were used to compare scores for gender and country, while analysis of variance was used to compare age groups. Results of these 3 tests are shown in Table 5. None of these tests were significant (all Ps $>0.05$ ). Hence, adolescents assessed their health similarly, regardless of whether they were girls or boys, from Croatia or Germany, or what age group they belonged to.

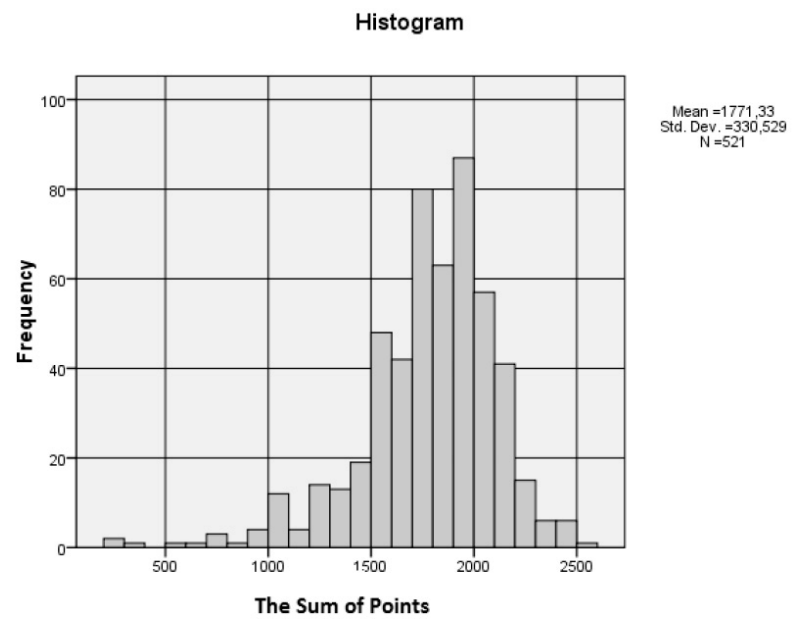

Figure 2. Composite health scores $(\mathrm{N}=521)$

Table 5. Differences in composite health scores based on gender, country of origin, and age

\begin{tabular}{|c|c|c|c|c|c|c|c|}
\hline $\mathrm{Nr}$ & Variable & $\begin{array}{l}\text { Group of } \\
\text { respondents }\end{array}$ & $\begin{array}{l}\mathrm{N}_{1} \\
\mathrm{~N}_{2}\end{array}$ & Mean & $\begin{array}{l}\text { Standard } \\
\text { deviation }\end{array}$ & $\mathrm{t}$ & $P$ \\
\hline 1. & $\begin{array}{l}\text { Gender of } \\
\text { adolescents }\end{array}$ & $\begin{array}{l}\text { male } \\
\text { female }\end{array}$ & $\begin{array}{l}194 \\
324\end{array}$ & $\begin{array}{l}1770 \\
1777\end{array}$ & $\begin{array}{l}295 \\
346\end{array}$ & 0.235 & 0.815 \\
\hline 2. & $\begin{array}{l}\text { Adolescent's } \\
\text { country of origin }\end{array}$ & $\begin{array}{l}\text { Croatia } \\
\text { Germany }\end{array}$ & $\begin{array}{l}362 \\
159\end{array}$ & $\begin{array}{l}1774 \\
1766\end{array}$ & $\begin{array}{l}314 \\
365\end{array}$ & 0.228 & 0.819 \\
\hline 3. & $\begin{array}{l}\text { Age of } \\
\text { adolescents }\end{array}$ & $\begin{array}{l}11-12 \text { у.о. } \\
13-14 \text { у.о. } \\
\text { 15-16 у.о. } \\
17-18 \text { у.о. }\end{array}$ & $\begin{array}{r}40 \\
121 \\
284 \\
69\end{array}$ & $\begin{array}{l}1825 \\
1764 \\
1769 \\
1802\end{array}$ & $\begin{array}{l}250 \\
335 \\
339 \\
285\end{array}$ & 0.539 & 0.656 \\
\hline
\end{tabular}


Participants were classified into three groups based on their composite health scores based on approximate quartile values; that is, participants approximately in the bottom quartile were classified as "worse," those in the two middle quartiles as "medium," and those in the top quartile as "better." Chi-square tests were used to compare these three groups according to gender, country of origin, and age. There was no statistically significant connection between respondent gender and health quality $\left(\chi^{2}=0.276 ; \mathrm{df}=2 ; \mathrm{N}=518 ; \mathrm{P}=0.871\right)$. There were also no significant connections between respondent age and health quality $\left(\chi^{2}=2.034 ; \mathrm{df}=6 ; \mathrm{N}=514\right.$; $\mathrm{P}=0.917)$. However, there were significant connections between respondents' country of origin and health quality $\left(\chi^{2}=6.998 ; \mathrm{df}=2 ; \mathrm{N}=521 ; \mathrm{P}=0.030\right)$.

Relative frequencies (percentages) were calculated to illustrate the nature of the connection between country of origin and health classification. Notably, $23 \%$ of Croatian compared to $31 \%$ of German respondents were in bad health. Additionally, 54\% percent of Croatian compared to $42 \%$ of German adolescents reported medium health. Hence, the results suggest that German respondents evaluated their health as being compared to Croatians. However, this result is not in accordance with the T-test results that showed that there was no significant difference between the average composite health scores of those two countries. The mean score in Croatia was 1776, in Germany 1766. Therefore, Germany had a lower average, although that difference was not statistically significant $(\mathrm{P}=0.819)$ as previously stated.

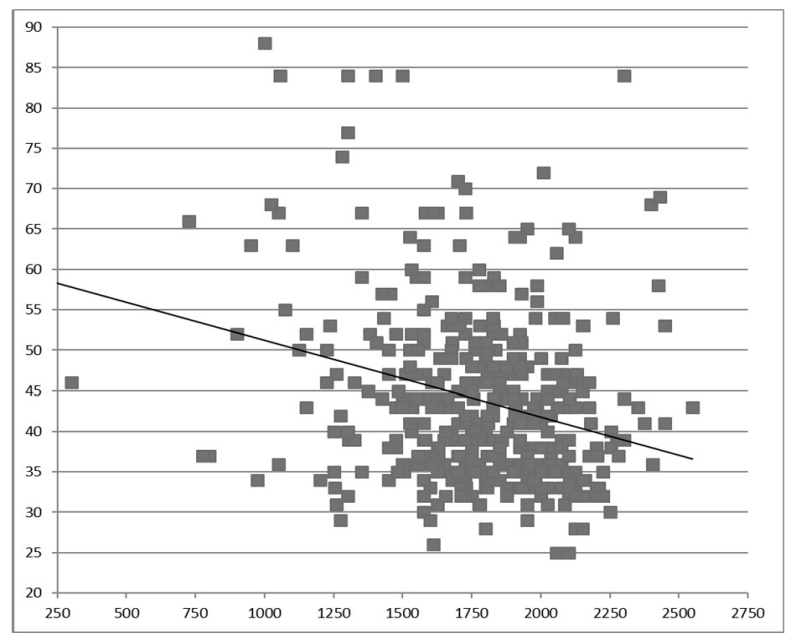

Figure 3. Correlation between health quality and Internet addiction $(\mathrm{N}=459)$

\section{Statistical analysis of the relationship between health status and Internet addiction}

Spearman's correlation and Chi-square tests were used to examine the relationship between health status and Internet addiction. Figure 3 displays the correlation between composite health score (the $\mathrm{X}$ axis,) and Internet addiction score (the $\mathrm{Y}$ axis). There was a significant negative correlation $(\rho=-0.23, \mathrm{P}<0.001, \mathrm{~N}=459)$. This indicates that greater health is associated with lower levels of addiction and vice versa.
The number of participants with severe Internet addiction was very small. Hence, to allow a sufficient sample size to conduct the Chi-square tests, participants with severe and with moderate addiction were merged into a single category and compared with non-addicted participants.

It showed a highly significant relationship between adolescents' health quality and their Internet addiction status $\left(\chi^{2}=24.874 ; \mathrm{df}=2 ; \mathrm{N}=459 ; \mathrm{P}<0.001\right)$. Among all adolescents in bad health, $39 \%$ of them were moderately or severely addicted to the Internet; $20 \%$ of those with medium health, were moderately or severely addicted; $13 \%$ of those in good health, were moderately or severely addicted. Figure 4 graphically illustrates the cited percentages of moderate/severe Internet addicts according to their health classifications. Accordingly, the group of adolescents with better health have proportionally fewer Internet addicts, while, the group of adolescents with worse health, have a proportionally higher number of Internet addicts. This crucial research finding was further analyzed by gender, age, and country of origin.

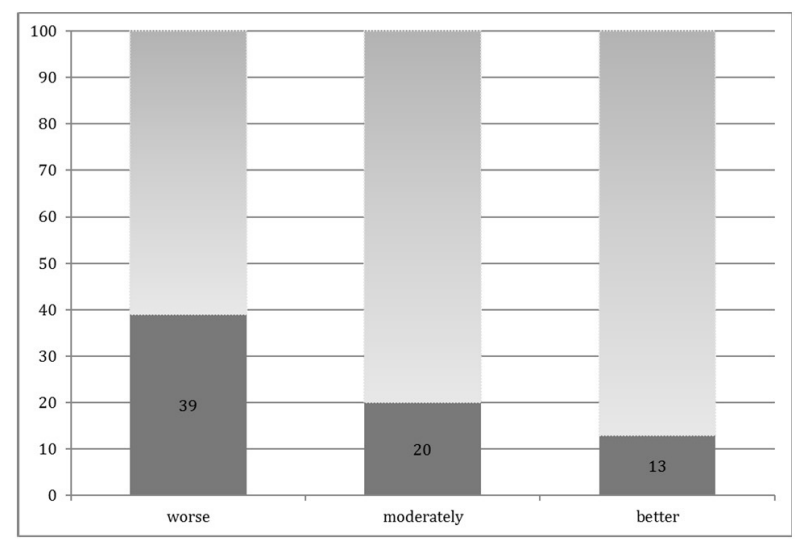

Figure 4. Proportions of moderately and severely Internet addicted adolescents (lower, darker part of the column) with different health classifications $(\mathrm{N}=459)$ in percentages

There was a statistically significant connection between the health quality of male adolescents and the degree of their Internet addiction $\left(\chi^{2}=12.780 ; N=169\right.$; $\mathrm{P}=0.002)$. The same conclusion was also valid for female adolescents $\left(\chi^{2}=13.090 ; \mathrm{N}=288 ; \mathrm{P}=0.001\right)$.

It was not possible to include the youngest (ages 1112, $\mathrm{N}=33$ ) and the oldest adolescents (ages 17-18, $\mathrm{N}=65$ ) in the Chi-square test for different age groups due to insufficient sample sizes. However, it was possible to analyze adolescents aged 13-14 and 15-16. There was a statistically significant connection between the health quality of adolescents aged 13-14 and the degree of their Internet addiction $\left(\chi^{2}=6.895 ; N=107\right.$; $\mathrm{P}=0.032)$. The same applied for adolescents aged 15-16 $\left(\chi^{2}=11.770 ; \mathrm{N}=248 ; \mathrm{P}=0.003\right)$.

There was a statistically significant connection between the health quality of Croatian adolescents and the degree of their Internet addiction $\left(\chi^{2}=21.063 ; N=310\right.$; $\mathrm{P}<0.001)$. The same was valid for adolescents from Germany $\left(\chi^{2}=14.204 ; \mathrm{N}=149 ; \mathrm{P}=0.001\right)$. 


\section{DISCUSSION}

Health status self-assessments between Croatian and German adolescents suggest differences in the following categories: general self-assessments of health, and health perception compared to peers. Ratings of German adolescents are somewhat better and more optimistic than those of Croatian adolescents only in 2 questions referring to general perception and change of health.

Croatian and German adolescents most commonly rated their health as the medium, in the categories of health perception over a year, a perception of physical functioning, and perception of recent feelings of despondency and happiness.

In ontogenesis of motoric development in adolescence period, one reaches a phase of stabilization which is linked to individual abilities and affinities, as well as a differentiation-related to gender. Adolescents from Croatia and Germany had relatively low rates of health problems, with an average rate of $9 \%$. Differences were apparent between the $7 \%$ of Croatian and the $14 \%$ of German adolescents who perceived pain. Hence, German adolescents were twice as likely to be in pain compared to Croatian adolescents. In the period of adolescence begins the phase of independence. Adolescents who are directed towards peer groups want to grow up as soon as possible.

Unlike Croatian, German adolescents are leaving their parents extremely early, 10 and over ten years earlier. The result of leaving this early is the appearance of anxiety, especially when they meet with problems with inadequate mental or physical growth. A situational variable like this can affect on a stronger feeling of pain (McGrath \& Gillespie 2001). This relates to all types of pain, except neck-pain, which was experienced by $5 \%$ of respondents, while $13 \%$ have experienced back-pain and $15 \%$ have had headaches.

The average daily amount of sitting has increased to 9.3 hours a day, and that is longer than people spend asleep (7.7 hrs.). Therefore, it is not surprising that a large percentage $(73 \%)$ of adolescents experience some consequences related to health and emotional problems. The percentages by country are $76 \%$ of adolescents from Croatia and $67 \%$ from Germany respectively. In a study performed by Andrijašević and Associates, a connection was found between the way free time was spent and subjective experiences of health indicated by a relatively large number of expressed difficulties that are more characteristic of old people than of students (Andrijašević et al. 2005).

A young person that spends 38 hours weekly at a computer weekly is already considered an Internet addict. Internet addiction demands involve long-term periods of sitting, looking at the monitor, using the keyboard, using the mouse, repeating identical moves, the irregular position of the body. This may help explain why younger people display problems associated with old age.

The inability to perform some work and other activities due to physical health or emotional difficulties were more common in Croatian than in German adolescents.
The change of social system, wartime suffering, displacement, privatization, rising unemployment, the consequences of war trauma in children and adults, a growing number of suicides and violent behavior, emigration, etc., are just some of the problems that the average Croatian family is faced with today and therefore adolescents, which then becomes an important indicator of their emotional health. For all other consequences of health problems, the reverse relationship was found; German adolescents more frequently reduced the time they spent working and in other activities, performed a smaller amount of work, and had difficulties in performing certain work and activities. Pain is a signaling mechanism that warns an individual about dysfunctions and danger in their bio-psychological and spiritual functioning. However, it may be noted that physical and emotional difficulties did not create problems in everyday life for most adolescents (61\%), although they created very significant problems for $5 \%$ of participants.

Regarding perceptions of mental health adolescents experienced a fullness of life, depression, tranquility and peace, as well as nervousness equally often. Every feeling serves its function, and the results suggest that the presence of depression, a fullness of life, tranquility, and nervousness is a consequence of the nature of adolescence and is related to the complete and normal development of personality.

Croatian and German adolescents experienced similar frequencies of positive feelings. To be precise, about half of adolescents in both countries almost always have these kinds of feelings frequently. Croatian and German adolescents also experienced similar frequencies of negative feelings. Two-thirds of adolescents in these two countries rarely or almost never have negative feelings.

Upon closer examination, adolescents from these two countries experience somewhat different individual positive and negative feelings. Among positive feelings, feelings of the fullness of energy and happiness are more frequent in Croatian adolescents, while the feeling of peace and tranquility are more common in Germans. Negative feelings of nervousness, fatigue, and exhaustion are less represented in Croatia than in Germany.

Fatigue and exhaustion are mostly connected to a stressful way of life (Bültmann et al. 2002). Furthermore, chronic fatigue has negative consequences for health and $73 \%$ of people with chronic fatigue have an increased risk for different illnesses (Eriksen \& Bruusgaard 2004). A low level of bodily activities is a predictor of chronic fatigue (Eriksen et al. 2003). Bodily activity in free time reduces deterioration in physical health (Kaaria et al. 2009).

The results showed that feelings of nervousness, fatigue, and exhaustion were less represented in Croatia, while there were no differences in perceiving feelings of despondency, depression, and sorrow.

There was no difference in perception of health status change among Croatian and German adolescents; that is, there were no differences in whether physical health and emotional problems disturbed or did not disturb their 
social activities. The majority of adolescents $(70 \%$ of them) rarely and never experienced such disturbances.

Subjective ratings of general perceptions of health did not differ with respect to claims that "I get ill more easily than other people," "I am healthy as anyone else I know," "I think my health will worsen," and "My health is excellent. Croatian and German adolescents had a similar tendency to become ill (about 15\%). Two-thirds of participants denied a tendency to become ill.

There were no differences in perceptions of health and social functioning between Croatian and German adolescents regarding any variables.

Interventions based on social planning can be highly effective when they target individuals at the earliest stages of development. However, social planners must be careful not to intervene in ways that disrupt living conditions or interfere with normal development, to avoid causing psychological or social problems for individuals. Most adolescents (70\%) rarely or never experience disruptions in social functioning.

Adolescents were classified into three health status groups based on their composite health scores. Approximately $25 \%$ of adolescents rated their health as bad, $51 \%$ of them rated it medium, and $24 \%$ rated their health as good. Retrospect on own health mostly superficial and uninterested.

There were no statistically significant connections between respondents' gender, age, and health quality. A research sample of 844 subjects in a high school in Košice, Slovakia showed significant worsening of mental health and vitality in both genders, with boys self-reporting a larger worsening of health, while the differences between the proportions of respondents who reported either betterment or worsening were negligible (Salonna et al. 2008). However, there was a statistically significant connection between the country of the respondent and health quality in this study. Notably, the percentage of respondents who reported bad health was $23 \%$ for Croatians and $31 \%$ for Germans. Furthermore, the percentage of respondents with medium health was $54 \%$ in Croatia is, and $42 \%$ in Germany. Therefore, one can conclude that compared to Croatian respondents, Germans evaluate their health as being worse.

There was a highly significant statistical connection between adolescents' health quality and the degree of their addiction. Among all adolescents in bad health, $39 \%$ of them were moderately or severely addicted to Internet use; $20 \%$ of those in medium health were moderately or severely addicted; while only $13 \%$ of adolescents in good health were moderately or severely addicted. Accordingly, better adolescent health is associated with lower rates of Internet addiction, while worse health is associated with higher rates. Kim and Chun showed in their study that severe Internet addicts had the lowest ratings of promotion and perception of health status suggesting that Internet addiction has a negative influence on the health status of adolescents (Kim \& Chun 2005). Tendencies towards risky behavior increase a young person's chance of developing inappropriately, depending on their environment (Bijedić \& Bouillet 2009). Socioeconomic status affects how factors such as social networks, family, and individual health behavior influence risky behavior and should be understood within the broader concepts of health guidelines (Marmot \& Wilkinson 2005).

This key conclusion in the research is further analyzed according to adolescents' gender, age, and origin. Namely, one wishes to know is this conclusion valid with men as well as with women, with younger as well as with older adolescents, with Croatian adolescents as well as with German ones.

\section{CONCLUSION}

The goal of this research was to determine the existence of differences concerning health status, among adolescents in Croatia and Germany. Results of the analysis suggest the following conclusions.

Results of subjective health assessment between Croatian and German adolescents show statistically significant differences in the category of general health perception, although there was no difference in change perception compared to peers, health perception over a year, a perception of physical functioning of health, and recent feelings of despondency and happiness.

The inability to perform some work and other activities due to physical health or emotional disorders were more frequent in Croatian than German adolescents. German adolescents often reduced time spent working and other activities, did smaller amounts of work, and had difficulties performing some work and activity. However, it is noticeable that the physical and emotional health of most adolescents (61\% of them) did not create problems in everyday life. On the other hand, $5 \%$ of them experienced substantial problems.

Feelings of nervousness, fatigue, and exhaustion were less represented in Croatia, while there were no differences in perceiving feelings of despondency, depression, and sorrow.

Furthermore, most adolescents (70\%) were not impeded by physical health and emotional problems in social activities.

It can be seen that $23 \%$ of Croatian respondents had bad health, while $31 \%$ of Germans did. Additionally, $54 \%$ in Croatia had medium health, compared to $42 \%$ in Germany. Hence, one can conclude that German respondents evaluated their health worse than Croatians did.

There was a highly significant statistical connection between adolescents' health quality and the degree of their addiction. Among all adolescents in bad health, $39 \%$ were moderately or severely addicted to Internet use; $20 \%$ of those in medium health, were moderately or severely addicted; and only $13 \%$ of those in good health were moderately or severely addicted. Accordingly, adolescents in better health are proportionately less likely to be Internet addicts, while conversely, those in worse health are proportionately more likely to be Internet addicts. 
Acknowledgements: None.

Conflict of interest: None to declare.

\section{Contribution of individual authors:}

Silvana Karacic: design of the study, collection and interpretation of data, writing.

Stjepan Oreskovic: interpretation of results, manuscript design, editing.

\section{References}

1. Andrijašević $M$, Paušić J, Bavčević $T \&$ Ciliga D: Participation in leisure activities and self-perception of health in the students of the University of Split. Kinesiology 2005; 37:21-31.

2. Bijedić $M \&$ Bouillet D: Rizična ponašanja učenika srednjih škola $i$ dopivljaj kvalitete razredno nastavnog ozra?ja. Odgojne znanosti 2009; 9:113-132.

3. Bowling A: Measuring health: a review of quality of life measurement scales. Milton Keynes: Open University Press, 1991.

4. Bültmann U, Kant IJ, Kasl SV, Schröer KA, Swaen GM \& Van den Brandt PA: Lifestyle factors as risk factors for fatigue and psychological distress in the working population: prospective results from the Maastricht Cohort Study. J Occup Env Med 2002; 44:116-124.

5. Chuang YC: Massively Multiplayer Online Role-Playing Game-Induced Seizures: A Neglected Health Problem in Internet Addiction. Cyberpsychol Behav 2006; 9:451-456.

6. Eriksen $W$, Bruusgaard D \& Knardahl S: Work factors as predictors of sickness absence. A 3-month prospective study of nurses' aides. Occup Environ Med 2003; 60:271-278.

7. Eriksen $W$ \& Bruusgaard D: Do physical leisure time activities prevent fatigue? A 15 month prospective study of nurses' aides. Br J Sports Med 2004; 38:331-336.

8. Guo SS, Wu W, Chumlea WC \& Roche AF: Predicting overweight and obesity in adulthood from body mass index values in childhood and adolescence. Am J Clin Nutr 2002; 76:653-8.

9. Harris KM, Gordon-Larsen P, Chantala $K \&$ Udry JR: Longitudinal trends in racelethnic disparities in leading health indicators from adolescence to young adulthood. Arch Pediatr Adolesc Med 2006; 160:74-81.

10. Idler EL: Self-assessed health and mortality: a review of studies. International Review of Health Psychology, Volume 1. John Wiley \& Sons Ltd New York 1992; 1:33-54.

11. Kaaria S, Solovieva $S$ \& Leino-Arjas P: Associations of low back pain with neck pain. A study of industrial employees with 5-, 10-, and 28-year follow-ups. Eur J Pain 2009; 13:406-411.

12. Kim JS, Chun BC: Association of Internet addiction with health promotion lifestyle profile and perceived health status in adolescents. J Prev Med Public Health 2005; 38:53-60.
13. Lalonde M: A new perspective on the health of Canadians. Ottawa: Government of Canada, 1974.

14. Marmot M \& Wilkinson R: Social Determinants of Health. 2nd ed. New York City: Oxford University Press, 2005.

15. McGrath PA \& Gillespie J: Pain assessment in children and adolescent. U Turk, D.C. i Melzack, R. (Eds.). Handbook of pain assessment, 2001; 97-118, London: The Guilford Press.

16. Rakowski W, Mor $V$ \& Hiris J: An investigation of nonresponse to self-assessments of health by older people. J Aging Health 1994; 6:469-488.

17. Rumpf HJ, Meyer C, Hapke U \& John U: Screening for mental health: validity of the MHI-5 using DSM-IV Axis I psychiatric disorders as gold standard. Psychiatry Res 2001; 105:243-253.

18. Rumpf HJ, Meyer C, Hapke U \& John U: Screening for mental health: validity of the MHI-5 using DSM-IV Axis I psychiatric disorders as gold standard. Psychiatry Res 2001; 105:243-253.

19. Saisan J, Smith M, Robinson L \& Segal J: Internet and Computer Addiction: Signs, Symptoms and Treatment [Internet]. 2012. Available from: http://www.helpguide. org/mental/internet cybersex addiction.htm/>.

20. Salonna S, Middel B, Sleskova M, Geckova AM, Sijmen A, Johan WR, Groothoff $J$ \& Van Dijk JP. Pogoršanje zdravlja nije jedina mogucenost za adolescente: poboljšanje samoprocijenjenog zdravlja u mladicea $i$ djevojaka u dobi izmeðu 15 i 19 godina. CMJ 2008; 49:66-75.

21. Santalahti P, Aromaa M, Sourander A, Helenius $H \&$ Piha J: Have there been changes in children's psychosomatic symptoms? A 10-year comparison from Finland. Pediatrics 2005; 115:434-442.

22. Satia JA, Kristal AR, Curry $S$ \& Trudeau E: Motivations for healthful dietary change. Public Health Nutr 2001; 4:953-959.

23. Steffes-Hansenb $S$ \& Tsaoa JC: Predictors for internet usage of teenagers in the United States: A multivariate analysis. J Market Comm 2008; 14:171-192.

24. Weinstein MC, Berwick DM, Goldman PA, Murphy JM \& Barsky AJA: Comparison of three psychiatric screening tests using receiver operating characteristic (ROC) analysis. Med Care 1989; 27:593-607.

25. Widyanto L \& McMurran M: The psychometric properties of The Internet Addiction Test. Cyberpsychol Behav 2004; 7:443-450.

26. Wilkinson $R \&$ \& Marmot M: Social determinants of health. The solid facts. Geneva: WHO Regional Office for Europe, 2003.

27. Xavier MK, Pitangui AC, Silva GR, Oliveira VM, Beltr Pitangui AC, Silva GR, Oliveira VM, Beltrao NB \& Araújo RC: Prevalence of headache in adolescents and association with use of computer and videogames. Cien Saude Colet 2015; 20:3477-86. doi: 10.1590/1413812320152011.19272014.

28. Young KS: Internet addiction: The emergence of a new clinical disorder. Cyberpsychol Behav 1998; 1:237-244.

Correspondence:

Silvana Karacic, $M D$

Healthy Center Sveti Kriz Trogir

Ulica Domovinske zahvalnosti 1, Trogir, Croatia

E-mail:hotel-sveti-kriz@st.t-com.hr 